\title{
Unplanned reattendances at the paediatric emergency department within 72 hours: a one-year experience in $\mathrm{KKH}$
}

\author{
Guan Lin $\underline{G o h}^{1,2}$, MBBS, BMedSc, Peiqi $\underline{\text { Huang }}{ }^{1,2}$, MBBS, Man Ching Patrick Kong ${ }^{1}$, MBBS, So-Phia $\underline{\text { Chew }^{1}}$, MBBS, MRCPCH,
} Sashikumar Ganapathy ${ }^{1}$, MB Bch BAO, MRCPCH

\begin{abstract}
INTRODUCTION Unscheduled reattendances at the paediatric emergency department may contribute to overcrowding, which may increase financial burdens. The objectives of this study were to determine the rate of reattendances and characterise factors influencing these reattendances and hospital admission during the return visits.

METHODS Medical records of all patients who attended the emergency department at KK Women's and Children's Hospital, Singapore, from 1 June 2013 to 31 May 2014 were retrospectively reviewed. We collected data on patient demographics, attendance data and clinical characteristics. Planned reattendances, recalled cases, reattendances for unrelated complaints and patients who left without being seen were excluded. A multivariate analysis was conducted to determine the odds ratio of variables associated with hospital admission for reattendances.

RESULTS Of 162,566 children, 6,968 (4.3\%) returned within 72 hours, and 2,925 (42.0\% of reattendance group) were admitted on their return visits. Children more likely to reattend were under three years of age, Chinese, triaged as Priority 2 at the first visit, and were initially diagnosed with respiratory or gastrointestinal conditions. However, children more likely to be admitted on their return visits were over 12 years of age, Malay, had a higher triage acuity or were uptriaged, had the presence of a comorbidity, and were diagnosed with gastrointestinal conditions.

CONCLUSION We identified certain subgroups in the population who were more likely to be admitted if they reattended. These findings would help in implementing further research and directing strategies to reduce potentially avoidable reattendances and admissions.
\end{abstract}

Keywords: admission, emergency department, overcrowding, reattendances, return visits

\section{INTRODUCTION}

The growing use of emergency departments (EDs) has raised the importance of reducing avoidable reattendances. Patients returning to the ED within 72 hours of their initial presentation may contribute to overcrowding, ${ }^{(1-4)}$ which can lead to delayed treatment, patient dissatisfaction, straining of ED resources and increased healthcare costs. ${ }^{(1,2,5,6)}$ Reattendances may be due to illness progression ${ }^{(3,7,8)}$ or parental preference for ED care, ${ }^{(5)}$ but may also reflect failure to appropriately diagnose, treat and communicate follow-up advice at the first visit. ${ }^{(2,3,7-9)}$ In the paediatric population, parental concern or anxiety may play a significant role. ${ }^{(3,7,10)}$ Higher reattendance rates may, therefore, indicate suboptimal clinical care or failure to address parental concerns at the first visit. Consequently, the incidence of unplanned reattendances is regarded as a quality-of-care indicator that drives the improvement of clinical care and communication delivered at the initial visit. ${ }^{(3,4,11,12)}$ There is also an increasing focus on admissions for return visits, as high admission rates may represent medical errors such as misdiagnoses or inappropriate treatment. $^{(8)}$

A majority of studies have associated reattendance with young age; higher acuity; attendance during the busiest hours; presence of chronic illness; infectious disease or respiratory diagnoses; and higher rates of admission. ${ }^{(1-3,7,9,13)}$ In particular, children with chronic diseases have complex multidisciplinary care needs and may present to the ED more frequently when alternative sources of care are not available. ${ }^{(14-16)}$

In the present study, our primary objective was to determine the rate and characteristics of reattendances at our paediatric ED within 72 hours from the first visit. Our secondary objective was to identify demographic and clinical factors that may influence admission rates of reattendances. Factors of particular interest include patient age, time of initial presentation, triage acuity level, presence of comorbidities and diagnoses. Through this study, we hope to identify underlying factors associated with unplanned reattendances and thereby aid the implementation of strategies to address overcrowding, improve communication and, ultimately, enhance patient care.

\section{METHODS}

The emergency department at KK Women's and Children's Hospital $(\mathrm{KKH})$, the largest tertiary paediatric emergency department in Singapore, is open to any child younger than 16 years of age. We reviewed electronic medical records of all patients who reattended the $\mathrm{KKH}$ paediatric ED within 72 hours from 1 June 2013 to 31 May 2014. Planned reattendances, recalled cases, reattendances for unrelated complaints and patients who left without being seen were excluded. Data was extracted from the 


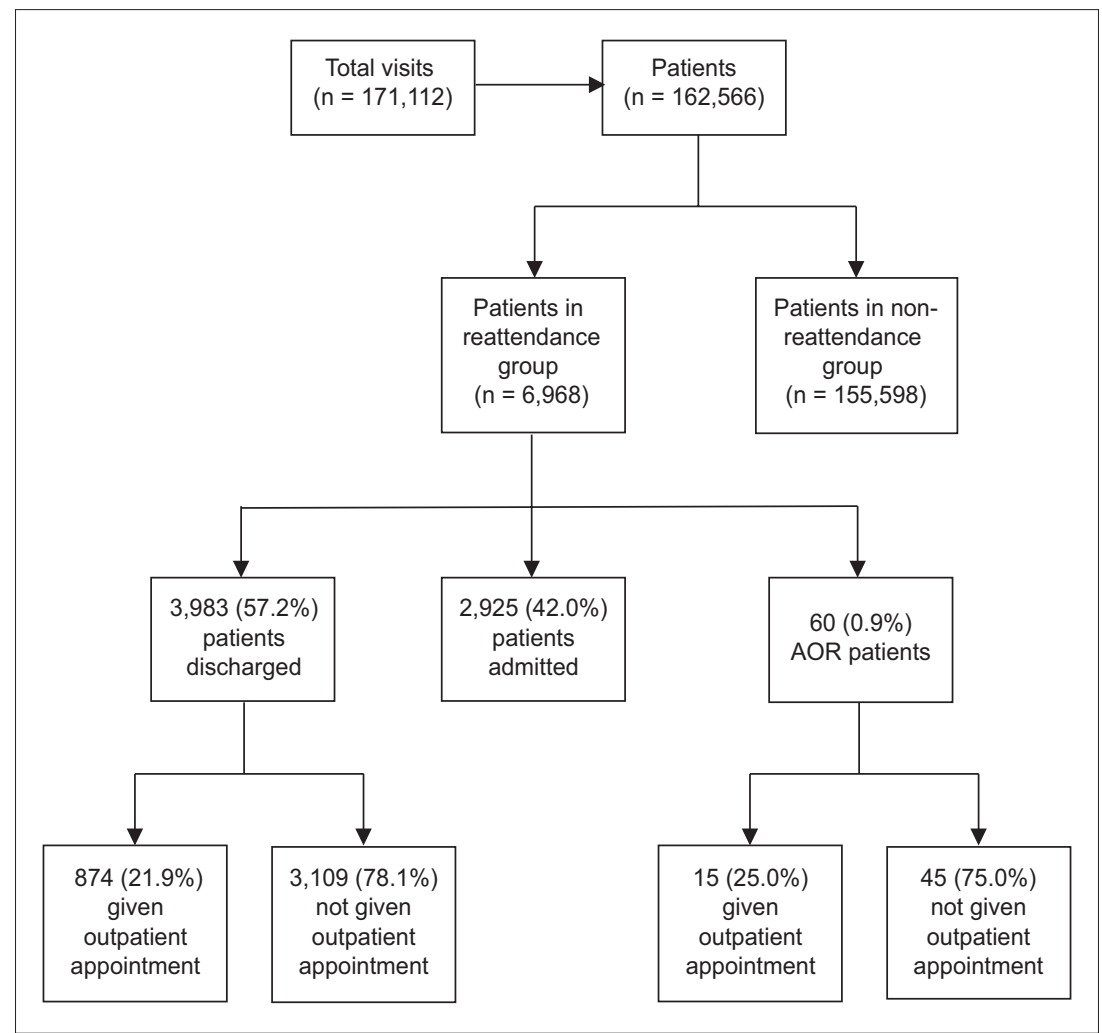

Fig. 1 Flowchart shows the reattendance visits, exclusion criteria and final disposition of patients who reattended the emergency department from 1 June 2013 to 31 May 2014. Exclusion criteria included planned reattendances (i.e. reviews for neonatal jaundice and dengue), recalled cases, reattendances for unrelated complaints and patients who left without being seen. AOR: discharged against medical advice.

ED's electronic medical database, Online Paediatric Emergency Care (OPEC). Data collected included: (a) patient demographics (age, race and gender); (b) attendance data (time of the first visit, acuity at the first and return visits, duration between the first and return visit, and level of seniority of the attending physician during the first visit); and (c) clinical characteristics (type of comorbidity, diagnoses at the first and return visits, and disposition at the return visit). The study was approved by the SingHealth Centralised Institutional Review Board.

The ED at our institution uses the Singapore Paediatric Triage scale, a four-level triage system that categorises patients into four priority categories: Priority 1, Priority 2 Plus, Priority 2, and Priority 3. Priority 1 refers to emergent cases that require immediate attention and may involve resuscitation. Priority 2 and 2 Plus refer to urgent cases that may deteriorate if not seen quickly; specifically, Priority 2 Plus cases require medical attention within ten minutes from the time of arrival at the ED. Priority 3 refers to nonurgent cases. Time of visit was defined as the time of registration during the first visit to the ED, classified as morning (8.30 am-4.30 pm), evening (4.30 pm-11 pm) or night (11 pm-8.30 am) based on the shift hours of the staff. The duration between the first and return visits was divided into: (a) $\leq 24$ hours; (b) $>24$ hours but $\leq 48$ hours; (c) $>48$ hours but $\leq 72$ hours; and (d) more than one return visit within a 72-hour period.

The comorbidities and diagnoses were classified according to the International Classification of Diseases, 10th revision. ${ }^{(17)}$ Each patient was reviewed by an attending physician whose seniority was classified as follows: a senior doctor is a trained specialist registrar and above; a resident doctor is enrolled in a training specialist programme (including paediatrics, emergency medicine and family medicine); and a non-resident doctor is not enrolled in a training specialist programme.

Statistical analysis was carried out using Microsoft Excel (Microsoft Corp, Redmond, WA, USA) and IBM SPSS Statistics version 19.0 (IBM Corp, Armonk, NY, USA). Categorical variables were compared using chi-square test and continuous variables using Student's $t$-test. A multivariate logistic regression model was developed to estimate the odds ratio (OR) for factors that influenced admission rates for ED reattendances. Adjusted ORs were expressed with 95\% confidence interval and statistical significance was set at $p<0.05$. Variables used in our multivariate logistic regression model included ED reattendance, age, gender, race, staff shift at time of visit, initial diagnosis, presence of comorbidity, doctor's level of seniority and triage acuity level.

\section{RESULTS}

In the one-year study period, there were a total of 171,112 attendances at the ED involving 162,566 patients. 6,968 patients $(4.3 \%)$ reattended the ED within a 72 -hour period and 155,598 patients did not reattend. On the return visit, of the 6,968 patients who reattended, 3,983 (57.2\%) were discharged, $2,925(42.0 \%)$ were admitted and $60(0.9 \%)$ were discharged against medical advice. Of those who were discharged, $874(21.9 \%)$ patients were given a follow-up appointment and $3,109(78.1 \%)$ were not. Fig. 1 shows the selection process, reattendances and patients' disposition during the one-year study period. Table I compares the characteristics of patients who reattended the ED and those who did not reattend, while 
Table I. Demographic and clinical characteristics by emergency department reattendance within 72 hours.

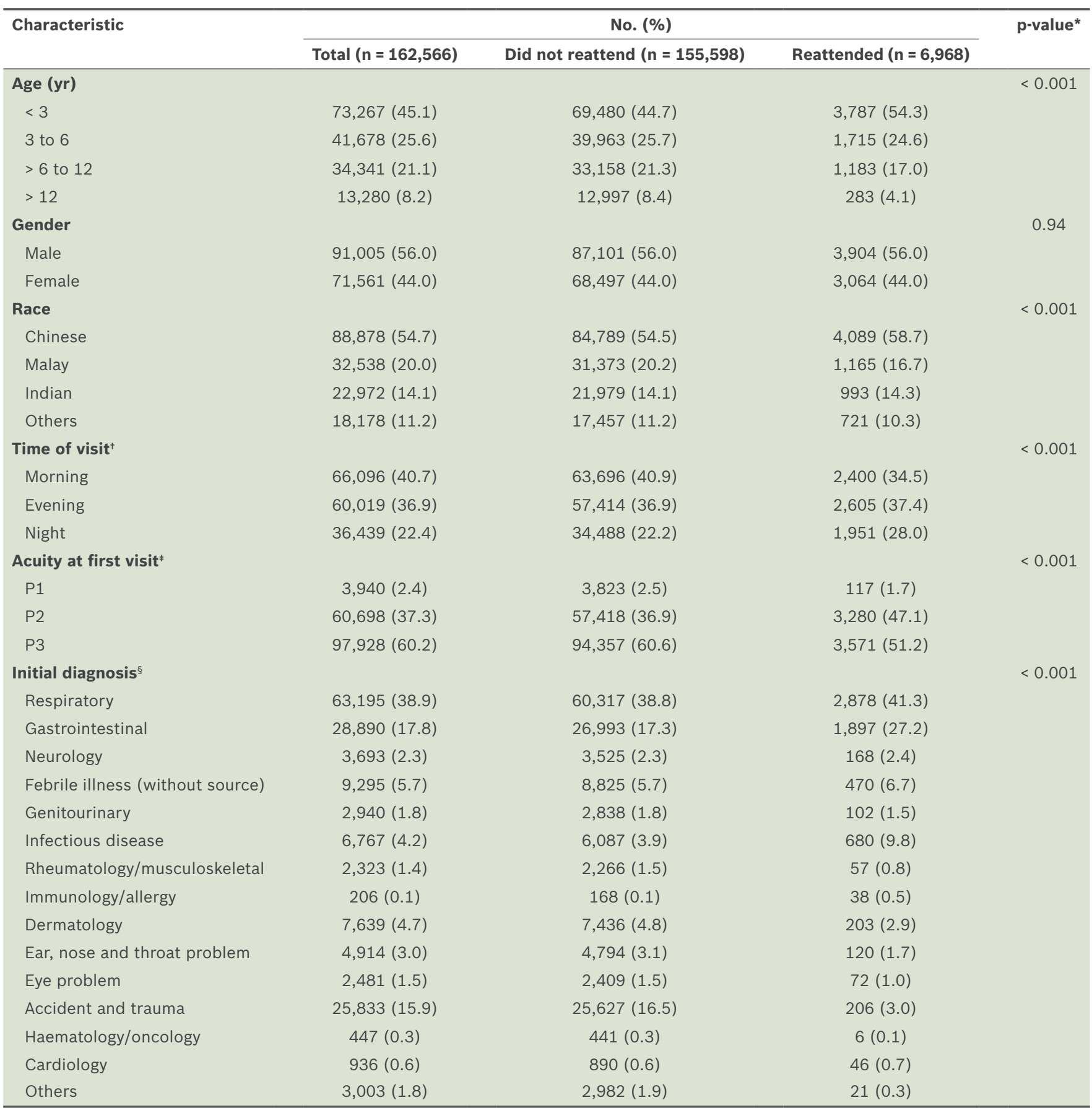

*Data was analysed using chi-square test. †Information on 12 patients who reattended was missing. Percentages were calculated based on available data. $₹$ Acuity presented as priority on the Singapore Paediatric Triage scale. \$Information on 4 patients who reattended was missing. Percentages were calculated based on available data. P: priority.

Table II shows the characteristics of patients who were admitted and not admitted at reattendance. The results of our multivariate logistic regression analysis of admitted reattending patients are provided in Table III.

Children under three years of age represented the largest proportion of all ED visits (45.1\%) and reattendances (54.3\%). However, children over 12 years of age were more likely to be admitted on their return visits when compared to those under three years of age (OR 1.50, Cl 1.13-1.99; $p=0.005)$. The racial distribution of patients attending our ED was comparable to that of the general population. ${ }^{(18)}$ Malay children were more likely to be admitted on return visits compared to Chinese children (OR 1.55, $\mathrm{Cl} 1.34-1.79 ; \mathrm{p}<0.001)$. Priority 2 patients were more common among patients who reattended than among those who did not reattend $(47.1 \%$ vs. $36.9 \%$; $<0.001)$. In addition, patients who were initially triaged as Priority 1 and Priority 2 cases were more likely than Priority 3 cases to be admitted on their return visit $(p<0.001) .23 .8 \%(n=1,645)$ of reattendances had a change in triage acuity, of which $91.2 \%(n=1,501)$ were uptriaged from Priority 3 to Priority 2. Of note, there were 44 patients who were uptriaged from Priority 3 to Priority 1 , which was $0.6 \%$ of the total patients who reattended. Multiple reattendances within 72 
Table II. Demographic and clinical characteristics by emergency department (ED) admission at reattendance ( $\mathrm{n}=6,908)$.

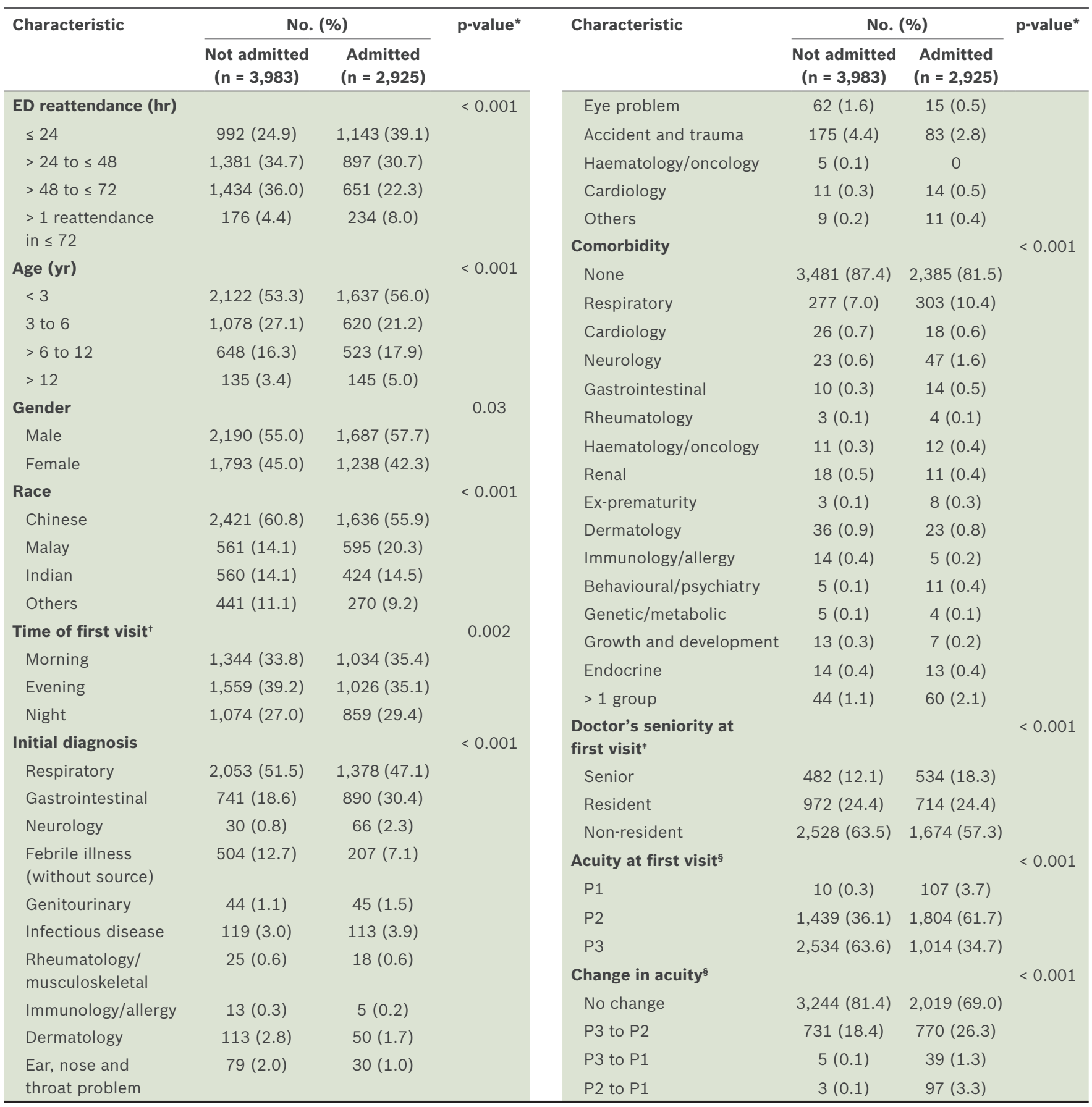

Patients who were discharged against medical advice were excluded from the analysis $(n=60)$. Data was analysed using chi-square test. ${ }^{\dagger}$ Information on 6 patients who were admitted and 6 patients who were not admitted was missing. Percentages were calculated based on available data. $¥$ Information was missing on 3 patients who were admitted and 1 patient who was not admitted. Percentages were calculated based on available data. $\S$ Acuity presented as priority on the Singapore Paediatric Triage scale. P: priority.

hours were more likely to be associated with admission on the return visit than single reattendance within 24 hours (OR 1.56, $\mathrm{Cl} 1.24-1.97, \mathrm{p}<0.001)$. Among patients who reattended within 24 hours, a significantly higher proportion were admitted than discharged (39.1\% vs. $24.9 \% ; p<0.001)$.

Most reattendances were seen by non-residents $(60.9 \%$, $\mathrm{n}=4,202)$ in the first visit, followed by residents $(24.4 \%$, $\mathrm{n}=1,686)$ and senior doctors $(14.7 \%, \mathrm{n}=1,016)$. Children attended to by a resident or a non-resident doctor during the first visit were less likely to be admitted compared to those attended to by a senior doctor $(\mathrm{p}<0.001) .15 .1 \%(\mathrm{n}=1,042)$ of the reattendance population had one or more comorbidity; respiratory comorbidities were most frequently observed. The presence of comorbidities was significantly associated with hospital admission (OR 1.32, Cl 1.13-1.54; $\mathrm{p}<0.001$ ).

Respiratory and gastrointestinal diagnoses were the two most common diagnoses in both overall ED attendances $(38.9 \%$ and $17.8 \%$, respectively) as well as reattendances $(41.3 \%$ and 
Table III. Multiple logistic regression analysis of the characteristics of patients who were admitted at reattendance.

\begin{tabular}{|c|c|c|}
\hline Characteristic & $\begin{array}{c}\text { Adjusted odds ratio } \\
(95 \% \mathrm{Cl})\end{array}$ & p-value \\
\hline \multicolumn{3}{|l|}{ ED reattendance $(\mathrm{hr})$} \\
\hline$\leq 24$ & ref & - \\
\hline$>24$ to $\leq 48$ & $0.63(0.56-0.72)$ & $<0.001$ \\
\hline$>48$ to $\leq 72$ & $0.48(0.41-0.55)$ & $<0.001$ \\
\hline$>1$ reattendance in $\leq 72$ & $1.56(1.24-1.97)$ & $<0.001$ \\
\hline \multicolumn{3}{|l|}{ Age (yr) } \\
\hline$<3$ & ref & - \\
\hline 3 to 6 & $0.79(0.69-0.90)$ & $<0.001$ \\
\hline$>6$ to 12 & $1.13(0.97-1.31)$ & 0.12 \\
\hline$>12$ & $1.50(1.13-1.99)$ & 0.005 \\
\hline \multicolumn{3}{|l|}{ Gender } \\
\hline Male & ref & - \\
\hline Female & $0.95(0.86-1.06)$ & 0.38 \\
\hline \multicolumn{3}{|l|}{ Race } \\
\hline Chinese & ref & - \\
\hline Malay & $1.55(1.34-1.79)$ & $<0.001$ \\
\hline Indian & $1.11(0.95-1.30)$ & 0.19 \\
\hline Others & $0.99(0.82-1.19)$ & 0.88 \\
\hline \multicolumn{3}{|l|}{ Time of visit } \\
\hline Morning & ref & - \\
\hline Evening & $0.78(0.69-0.89)$ & $<0.001$ \\
\hline Night & $0.88(0.77-1.00)$ & 0.06 \\
\hline \multicolumn{3}{|l|}{ Initial diagnosis } \\
\hline Respiratory & ref & - \\
\hline Gastrointestinal & $1.96(1.71-2.23)$ & $<0.001$ \\
\hline Neurology & $2.35(1.48-3.74)$ & $<0.001$ \\
\hline Febrile illness (without source) & $0.70(0.58-0.84)$ & $<0.001$ \\
\hline Genitourinary & $1.59(1.00-2.54)$ & 0.05 \\
\hline Infectious disease & $1.90(1.43-2.53)$ & $<0.001$ \\
\hline $\begin{array}{l}\text { Rheumatology/ } \\
\text { musculoskeletal }\end{array}$ & $1.05(0.54-2.04)$ & 0.89 \\
\hline Immunology/allergy & $0.58(0.19-1.74)$ & 0.33 \\
\hline Dermatology & $0.69(0.48-0.99)$ & 0.04 \\
\hline Ear, nose and throat problem & $0.61(0.39-0.96)$ & 0.03 \\
\hline Eye problem & $0.37(0.20-0.67)$ & 0.001 \\
\hline Accident and trauma & $0.68(0.50-0.92)$ & 0.011 \\
\hline Haematology/oncology & $1.00(0.00-0.00)$ & $<0.001$ \\
\hline Cardiology & $1.16(0.50-2.73)$ & 0.73 \\
\hline Others & $1.23(0.46-3.33)$ & 0.68 \\
\hline \multicolumn{3}{|l|}{ Comorbidity } \\
\hline None & ref & - \\
\hline Present & $1.32(1.13-1.54)$ & $<0.001$ \\
\hline \multicolumn{3}{|l|}{ Doctor's seniority at first visit } \\
\hline Senior & ref & - \\
\hline Resident & $0.70(0.59-0.83)$ & $<0.001$ \\
\hline Non-resident & $0.62(0.53-0.73)$ & $<0.001$ \\
\hline \multicolumn{3}{|l|}{ Acuity at first visit ${ }^{*}$} \\
\hline $\mathrm{P} 1$ & $21.93(11.27-42.67)$ & $<0.001$ \\
\hline P2 & $2.97(2.67-3.31)$ & $<0.001$ \\
\hline P3 & ref & - \\
\hline
\end{tabular}

*Acuity presented as priority $(P)$ on the Singapore Paediatric Triage scale. $\mathrm{Cl}$ : confidence interval; ref: reference group.
$27.2 \%$, respectively). In the reattendance population, patients with gastrointestinal diagnoses were more likely to be admitted (OR 1.96, Cl 1.71-2.23; p < 0.001) compared to those with respiratory diagnoses. Accident and trauma diagnoses accounted for only $3.0 \%$ of reattendances despite being the third most common diagnosis for overall ED visits.

\section{DISCUSSION}

With rising ED attendance rates, there has been a growing need to address the issue of overcrowding. ${ }^{(19,20)}$ Analysing factors associated with reattendances may aid in reducing potentially avoidable ED reattendances, and in turn reduce financial and healthcare burdens.

The present study found that the reattendance rate was $4.6 \%$ within a 72-hour period from the first ED visit. This was consistent with the average rate of $5 \%$ reported in previous studies. ${ }^{(1)}$ It has been reported that the rate of unplanned reattendances may reflect the quality of care provided by the ED. Our reattendance rate was well within the limits set by the American Academy of Paediatrics as well as the Department of Health in the United Kingdom. ${ }^{(21)}$

In addition, the admission rate among reattendances was $42.0 \%$. This was higher than the overall admission rate of $16.5 \%$ among ED patients at our institution over the same duration, which is a trend seen in most other EDs. ${ }^{(2,3,7)}$ Physicians may be more inclined to order additional investigations or have a lower threshold to admit patients at the return visit. ${ }^{(3)}$ For the paediatric population, parental anxiety plays a major role in influencing the disposition of the child. ${ }^{(7)}$

The patient's age was found to be inversely proportional to the reattendance rate at our ED, consistent with preceding studies. ${ }^{(1,7,9)}$ Young patients are often unable to express their discomfort, leading to ambiguity in signs and symptoms. Parents, especially first-time parents, may also have a lower threshold to revisit the ED for any change in symptoms or concerns in younger patients. Interestingly, we found that patients over 12 years of age were more likely to be admitted on their return visits compared to those aged under three years. Cho et al ${ }^{(3)}$ previously suggested that adolescents, as well as very young children, were more likely to revisit the ED. The present study showed that adolescents were less likely to revisit the ED, but were more likely to be admitted on their return visits. This could be related to their noncompliance to treatment or follow-up appointments. It may also reflect the higher tendency of true illness progression in adolescents compared to younger children, whose return visits may largely be influenced by parental anxiety. It may be worthwhile analysing this subgroup of patients to determine potential contributing factors that may influence admission rates.

Compared to patients of other races, the Malay patients in our study were more likely to be admitted on their return visits, possibly reflecting a higher incidence of chronic diseases and increased reliance on the ED for routine care. In addition, language barriers may impair understanding of discharge instructions, or limit accessibility to primary care resources. ${ }^{(22,23)}$ Previous studies have also identified differences in healthcare-seeking behaviours 
and medical care among various ethnic groups. ${ }^{(14,23-26)}$ Future interventions could include employing medical interpreters in the ED as well as improving accessibility to primary paediatric care in the community.

In terms of attendance characteristics, patients with a higher acuity level at initial triage were more likely to be admitted on the return visit, a trend clearly established in preceding studies. ${ }^{(1,13,22)}$ High-acuity patients are generally more unwell and may have returned because of illness progression. ${ }^{(13)} 91.5 \%$ $(n=107)$ of patients who were initially triaged as Priority 1 cases subsequently required admission. Uptriaging of acuity was also significantly associated with higher admission rates. These patterns should prompt clinicians to consider early admission in higheracuity cases. It is important to consider illness progression as an underlying cause of the increased rates of admission for children returning to the ED within 24 hours. This may be particularly true for children with respiratory conditions, as they may deteriorate within a short period. ${ }^{(27,28)}$ On the other hand, parental anxiety and increased pressure on the physician may account for the higher likelihood of admission of children who reattended multiple times.

Most of the reattendances were seen by non-resident doctors during the initial visit, a trend that reflects the general staffing distribution at $\mathrm{KKH}$. Consulting a doctor of greater seniority at the first visit was notably associated with a greater likelihood of subsequent admission. This may partially be attributed to the fact that higher acuity cases are often assigned to senior doctors. ${ }^{(13)}$ However, the association persisted even after adjusting for triage acuity level. Another postulation was the varying degree of safety netting advice given, as delivering clear and targeted advice ensures that patients with illness progression return in a timely manner. ${ }^{(29)}$ At the same time, other studies have shown that the level of training of the primary doctor was not significantly associated with admission rates. ${ }^{(13,30,31)}$

The presence of comorbidities was independently associated with higher likelihood of being admitted at reattendances, notably for respiratory comorbidities. Hence, healthcare institutions may wish to consider focusing interventions on respiratory conditions and increasing accessibility in the primary outpatient setting. Respiratory diagnoses were also reported as the most common diagnoses during return visits in other studies. ${ }^{(9)}$ This was not unexpected, as respiratory conditions have the potential to deteriorate more rapidly. However, we found that patients diagnosed with gastrointestinal complaints were more likely to be admitted compared to respiratory diagnoses, and the underlying cause and significance requires further investigation.

Being the largest tertiary paediatric hospital in Singapore, KKH was well-equipped to obtain a large sample size. Therefore, although our study was conducted at only one centre, we believe that the sample is representative of the country's paediatric population. Nevertheless, as this retrospective study relied on accurate data collection and documentation, interpretation may have been limited by information bias. Another limitation was the role of confounding factors, which was minimised by the use of multivariate logistic regression.
This study did not examine the association of reattendance rates with health insurance or caregiver-related factors, such as parental age and the level of parental education. Public insurance has often been associated with a higher reattendance rate compared to private insurance. ${ }^{(3,9,13)}$ Parental patterns of healthcare use have also been shown to influence the use of $E D$ visits for their children. ${ }^{(32)}$ Efforts to educate parents may potentially reduce the reattendance rate.

An earlier survey exploring reasons for nonurgent paediatric ED attendances at our ED found that most caregivers visited out of convenience, seeing it as a one-stop centre for care. ${ }^{(33)}$ Other reasons cited included parental perception of the urgency of an illness and lack of confidence in caring for a sick child. This survey can be extended to investigate reasons for ED reattendances.

$\mathrm{KKH}$ has a pre-existing dial-a-nurse service that is open to all parents. The feasibility of expanding the current service to include diversion of ambulance calls should be explored, as studies have shown that diverting emergency calls to a call-in nurse service may potentially reduce the number of ED attendances without increased adverse outcomes. ${ }^{(34-36)}$ Similarly, follow-up calls to subgroups of patients identified as having high reattendance rates, such as the young population in the present study, may help address parental concerns and alleviate the burden of ED reattendance. However, current studies have not demonstrated a reduction in reattendance rates in the paediatric $\mathrm{ED}^{(37,38)}$ and the practicality of such a strategy remains questionable.

Primary care plays an important role in reducing nonurgent attendances at the ED, but its accessibility may be limited after office hours. ${ }^{(39-42)}$ Studies have shown that introducing 24-hour primary care services led to a reduction in paediatric ED visits, particularly in nonurgent cases. ${ }^{(43)}$ Maintaining continuity of care with primary physicians may also reduce rates of admission for children with comorbidities. ${ }^{(44)}$ The importance of a primary physician for the adolescent population should also be reiterated, as this population has been identified as being at risk of readmission.

Observation units have been implemented in various paediatric EDs in countries such as Australia and the United States. They may facilitate closer monitoring of illness progression and increase parental satisfaction, thereby leading to a reduction in reattendance rates as well as avoidable admissions. ${ }^{(45-47)}$ Short-stay observational units are particularly helpful in reducing reattendance rates for children with respiratory and gastrointestinal complaints, which were identified in our study as the most common return visit diagnosis and readmission diagnosis, respectively.

In conclusion, this study is one of the first to analyse reattendances at the paediatric ED in an Asian population. Our reattendance rate shows the quality of care delivered at the ED. We identified higher admission rates in children who were over 12 years of age, Malay, triaged as higher acuity cases and had gastrointestinal diagnoses. These findings would aid in implementing further research as well as directing future strategies to reduce potentially avoidable reattendances and admissions. 


\section{REFERENCES}

1. Goldman RD, Ong M, Macpherson A. Unscheduled return visits to the pediatric emergency department-one-year experience. Pediatr Emerg Care 2006; 22:545-9.

2. Goldman RD, Kapoor A, Mehta S. Children admitted to the hospital after returning to the emergency department within 72 hours. Pediatr Emerg Care 2011; 27:808-11.

3. Cho CS, Shapiro DJ, Cabana MD, Maselli JH, Hersh AL. A national depiction of children with return visits to the emergency department within 72 hours, 2001-2007. Pediatr Emerg Care 2012; 28:606-10.

4. Department of Health, United Kingdom. A\&E Clinical Quality Indicators Implementation Guidance [online]. Available at: http://webarchive. nationalarchives.gov.uk/20130107105354/http:/www.dh.gov.uk/prod_ consum_dh/groups/dh_digitalassets/@dh/@en/@ps/documents/digitalasset dh_123055.pdf. Accessed August 22, 2015

5. Berry A, Brousseau D, Brotanek JM, Tomany-Korman S, Flores G. Why do parents bring children to the emergency department for nonurgent conditions? A qualitative study. Ambul Pediatr 2008; 8:360-7.

6. Hoot NR, Aronsky D. Systematic review of emergency department crowding: causes, effects, and solutions. Ann Emerg Med 2008; 52:126-36.

7. Alessandrini EA, Lavelle JM, Grenfell SM, Jacobstein CR, Shaw KN. Return visits to a pediatric emergency department. Pediatr Emerg Care 2004; 20:166-71.

8. Depiero AD, Ochsenschlager DW, Chamberlain JM. Analysis of pediatric hospitalizations after emergency department release as a quality improvement tool. Ann Emerg Med 2002; 39:159-63.

9. Zimmerman DR, McCarten-Gibbs KA, DeNoble DH, et al. Repeat pediatric visits to a general emergency department. Ann Emerg Med 1996; 28:467-73.

10. Maguire S, Ranmal R, Komulainen S, et al; RCPCH Fever Project Board. Which urgent care services do febrile children use and why? Arch Dis Child 2011; 96:810-6.

11. O'Loughlin K, Hacking KA, Simmons N, et al. Paediatric unplanned reattendance rate: A\&E clinical quality indicators. Arch Dis Child 2013; 98:211-3.

12. Bardach NS, Vittinghoff E, Asteria-Peñaloza R, et al. Measuring hospital quality using pediatric readmission and revisit rates. Pediatrics 2013; 132:429-36.

13. Jacobstein CR, Alessandrini EA, Lavelle JM, Shaw KN. Unscheduled revisits to a pediatric emergency department: risk factors for children with fever or infection-related complaints. Pediatr Emerg Care 2005; 21:816-21.

14. Yamamoto LG, Zimmerman KR, Butts RJ, et al. Characteristics of frequent pediatric emergency department users. Pediatr Emerg Care 1995; 11:340-6.

15. Gibson NP, Jelinek GA, Jiwa M, Lynch AM. Paediatric frequent attenders at emergency departments: a linked-data population study. J Paediatr Child Health 2010; 46:723-8.

16. Markham D, Graudins A. Characteristics of paediatric frequent presenters to an Australian emergency medicine network. J Paediatr Child Health 2013 ; 49:950-4.

17. World Health Organization. International Statistical Classification of Diseases and Related Health Problems 10th Revision. Available at: http://apps.who. int/classifications/icd10/browse/2016/en. Accessed May 19, 2015

18. Ministry of Health, Singapore. Population And Vital Statistics [online]. Available at: https://www.moh.gov.sg/content/moh_web/home/statistics/ Health_Facts_Singapore/Population_And_Vital_Statistics.html. Accessed August 23, 2015.

19. Boyle A, Beniuk K, Higginson I, Atkinson P. Emergency department crowding: time for interventions and policy evaluations. Emerg Med Int 2012; 2012:838610.

20. Cowan RM, Trzeciak S. Clinical review: Emergency department overcrowding and the potential impact on the critically ill. Crit Care 2005 ; 9:291-5.

21. Heyworth J. Emergency medicine-quality indicators: the United Kingdom perspective. Acad Emerg Med 2011; 18:1239-41.

22. Gallagher RA, Porter S, Monuteaux MC, Stack AM. Unscheduled return visits to the emergency department: the impact of language. Pediatr Emerg Care 2013; 29:579-83.

23. Chamberlain JM, Joseph JG, Patel KM, Pollack MM. Differences in severityadjusted pediatric hospitalization rates are associated with race/ethnicity. Pediatrics 2007; 119:e1319-24.

24. Boudreaux ED, Emond SD, Clark S, Camargo CA Jr; Multicenter Airway Research Collaboration Investigators. Race/ethnicity and asthma among children presenting to the emergency department: differences in disease severity and management. Pediatrics 2003; 111(5 Pt 1):e615-21.

25. James CA, Bourgeois FT, Shannon MW. Association of race/ethnicity with emergency department wait times. Pediatrics 2005; 115:e310-5.

26. Cone DC, Richardson LD, Todd KH, Betancourt JR, Lowe RA. Health care disparities in emergency medicine. Acad Emerg Med 2003; 10:1176-83.

27. Norwood A, Mansbach JM, Clark S, Waseem M, Camargo CA Jr. Prospective multicenter study of bronchiolitis: predictors of an unscheduled visit after discharge from the emergency department. Acad Emerg Med 2010; 17:376-82.

28. Benito-Fernández J, Onis-González E, Alvarez-Pitti J, et al. Factors associated with short-term clinical outcomes after acute treatment of asthma in a pediatric emergency department. Pediatr Pulmonol 2004; 38:123-8.

29. Roland D, Jones C, Neill S, Thompson M, Lakhanpaul M. Safety netting in healthcare settings: what it means, and for whom? Arch Dis Child Educ Pract Ed 2014; 99:48-53.

30. Gaucher N, Bailey B, Gravel J. Impact of physicians' characteristics on the admission risk among children visiting a pediatric emergency department. Pediatr Emerg Care 2012; 28:120-4.

31. de Vos-Kerkhof E, Geurts DH, Wiggers M, Moll HA, Oostenbrink R. Tools for 'safety netting' in common paediatric illnesses: a systematic review in emergency care. Arch Dis Child 2016; 101:131-9.

32. Serbin LA, Hubert M, Hastings PD, Stack DM, Schwartzman AE. The influence of parenting on early childhood health and health care utilization. J Pediatr Psychol 2014; 39:1161-74.

33. Ganapathy S, Lim SY, Kua JP, Ng KC. Non-Urgent Paediatric Emergency Department Visits: Why Are They So Common? A Singapore Perspective. Ann Acad Med Singapore 2015; 44:269-71.

34. Dale J, Green J, Reid F, Glucksman E, Higgs R. Primary care in the accident and emergency department: II. Comparison of general practitioners and hospital doctors. BMJ 1995; 311:427-30.

35. Dale J, Higgins J, Williams S, et al. Computer assisted assessment and advice for "non-serious" 999 ambulance service callers: the potential impact on ambulance despatch. Emerg Med J 2003; 20:178-83.

36. Dale J, Williams S, Foster T, et al. Safety of telephone consultation for "non-serious" emergency ambulance service patients. Qual Saf Health Care 2004; $13: 363-73$

37. Goldman RD, Wei JJ, Cheyne J, et al. Impact of follow-up calls from the pediatric emergency department on return visits within 72 hours: a randomized controlled trial. Pediatr Emerg Care 2014; 30:613-6.

38. Heath J, Dancel R, Stephens JR. Postdischarge phone calls after pediatric hospitalization: an observational study. Hosp Pediatr 2015; 5:241-8.

39. Christakis DA, Wright JA, Koepsell TD, Emerson S, Connell FA. Is greater continuity of care associated with less emergency department utilization? Pediatrics 1999; 103(4 Pt 1):738-42.

40. Kotagal UR, Schoettker PJ, Atherton HD, et al. Relationship between early primary care and emergency department use in early infancy by the medicaid population. Arch Pediatr Adolesc Med 2002; 156:710-6.

41. Petersen LA, Burstin HR, O'Neil AC, Orav EJ, Brennan TA. Nonurgent emergency department visits: the effect of having a regular doctor. Med Care 1998; 36:1249-55

42. Khangura JK, Flodgren G, Perera R, Rowe BH, Shepperd S. Primary care professionals providing non-urgent care in hospital emergency departments. Cochrane Database Syst Rev 2012; 11:CD002097.

43. Piehl MD, Clemens CJ, Joines JD. "Narrowing the Gap": decreasing emergency department use by children enrolled in the Medicaid program by improving access to primary care. Arch Pediatr Adolesc Med 2000; 154:791-5.

44. Christakis DA, Mell L, Koepsell TD, Zimmerman FJ, Connell FA. Association of lower continuity of care with greater risk of emergency department use and hospitalization in children. Pediatrics 2001; 107:524-9.

45. Crocetti MT, Barone MA, Amin DD, Walker AR. Pediatric observation status beds on an inpatient unit: an integrated care model. Pediatr Emerg Care 2004; 20:17-21.

46. Macy ML, Kim CS, Sasson C, Lozon MM, Davis MM. Pediatric observation units in the United States: a systematic review. J Hosp Med 2010; 5:172-82.

47. Ogilvie D. Hospital based alternatives to acute paediatric admission: a systematic review. Arch Dis Child 2005; 90:138-42. 